\title{
The Perception of Patients on the Service Quality Offered by Healthcare Professionals at Two Major Public Hospitals in South East Regional Health Authority (Serha), Jamaica
}

\author{
Jacqueline C Ellis ${ }^{1}$, Paul Andrew Bourne ${ }^{2 *}$, James Fallah ${ }^{2}$, Nicola Brown ${ }^{2}$, Cynthia Francis ${ }^{1}$ and Calvin \\ Campbell
}

${ }^{1}$ University of Technology, Jamaica

${ }^{2}$ Northern Caribbean University, Mandeville, Jamaica

\begin{abstract}
Globally, the new direction of many hospitals is to use the views of patients as a part of the feedback process in order to meet the expected service of users. The aim of the study is to examine patients' perception of quality of service performed by healthcare professionals at the Kingston Public and the Victoria Jubilee Hospitals in Jamaica. A cross sectional survey was conducted of 357 randomly selected patients who were admitted to a ward and subsequently discharged for home between January and April, 2018. The data were stored, retrieved and analyzed using the Statistical Packages for the Social Sciences (SPSS) for Windows, Version 25.0. The level of significance for this study is $5 \%$. The data were analyzed using both descriptive and inferential statistics. The Pearson's Chi-Square test was the only inferential measured to assess if a real statistical significant relationship exists between two categorical variables. Majority of the respondents sampled were female (62\%). Based on the gap for the overall service quality, service delivery is not meeting the general expectations of the patients who utilize the services of the two major hospitals in the South East Regional Health Authority (SER$H A)$ (i.e., $G a p=P-E=-1.0)$. The negative value indicates a dis-service, which is substantially owing to a lack of empathy (i.e., -1.4$)$, assurance $(-0.8)$, and responsiveness $(-0.9)$. Patients rated the empathy of the healthcare professionals as very low $(2.8 \pm 2.0, Q=-1.4)$, which account for the negative gap in service quality. The sampled clients of this study are somewhat highly satisfied with the service offered to them by healthcare professionals in two of the major public hospitals in Jamaica; but service deliverables are not meeting their expectations.
\end{abstract}

\section{Keywords}

Service quality, Patients' expectation of service delivery, Servqual, Service delivery

\section{Introduction and Background}

For decades, Jamaicans, particularly patients who use the public healthcare facilities, have been complaining about the poor quality of services offered to them by healthcare personnel [1-4]. In fact, a national probability cross-sectional study of 1,338 respondents found that the healthcare system in the island was identified as the $8^{\text {th }}$ leading national problems faced by the citizenry [5]. With the two major hospitals in the South East Regional Health Authority (SERHA) being major public healthcare facilities in the English-Speaking Caribbean, the findings from the work of Powell, Bourne \& Waller [5] as well as the complaints from users have provided the impetus for governments to examine how service quality care be improved, especially within the context of the importance of health to survivability and national development.

The two major hospitals in the South East Regional Health Authority (SERHA) are located in Kingston, Jamaica. The hospitals are in the midst of inner-city communities and a market. Those communities are Hannah Town, Matthews Lane, Regent Street and Denham Town communities and the Coronation Market in the Western Kingston Constituency. The General hospital was the first public health care hospital in Jamaica and it was opened on December 12, 1776 to serve the population (SERHA) [6]. Then in 1872, the Maternity hospital was commissioned to deal with maternity services in the island [7]. It is the only maternity hospital in Jamaica [8].

*Corresponding author: Paul Andrew Bourne, Statistician, Northern Caribbean University, Mandeville, Jamaica

Accepted: July 27, 2019

Published online: July 29, 2019

Citation: Ellis JC, Bourne PA, Fallah J, et al. (2019) The Perception of Patients on the Service Quality Offered by Healthcare Professionals at Two Major Public Hospitals in South East Regional Health Authority (Serha), Jamaica. Insights Anthropol 3(2):185-196 
Citation: Ellis JC, Bourne PA, Fallah J, et al. (2019) The Perception of Patients on the Service Quality Offered by Healthcare Professionals at Two Major Public Hospitals in South East Regional Health Authority (Serha), Jamaica. Insights Anthropol 3(2):185-196

The General hospital is a national public hospital and it is the largest trauma centre in the English-Speaking Caribbean [8]. SERHA [6] indicated that the General hospital provides critical services such as Haemodialysis and Radiotherapy for Jamaica and the English speaking Caribbean. It has a bed-capacity of 500 and on average, on an annual basis, sees approximately 90,000 patients in the Accident and Emergency Department [6]. The Maternity hospital, on the other hand, has a bed-capacity of 200 and on an annual basis sees about 23,927 patients $[7,9]$.

In 2015, 703, 683 patients visited the public hospitals in Jamaica and University Hospital of the West Indies (UHWI) [10]. Of the total number of people who visited public hospitals and UHWI in 2015, most of them visited the Kingston Public Hospital (12.9\% or 90, 902 patients), followed by Cornwall Regional Hospital (10.5\%, or 73, 832 patients), St. Ann's Bay Hospital (8.3\% or 58, 833 patients) and Bustamante Hospital for Children (7.5\% or 52, 786 patients) [10]. Over the last decade (2006-2015), the number of patients who visited the Accident and Emergency Department at GH has increased by $87.1 \%$ (or 42,316 patients) and this puts additional pressure on the already shortage of staff and equipment at the institution [11]. Like the Kingston Public Hospital (GH), the Victoria Jubilee Hospital (MH) has been plagued by a shortage of equipment and staff for some time [11].

The two major hospitals in the South East Regional Health Authority (SERHA) serve different socio-economic strata and significantly more of the patients are from the lower socioeconomic stratum. For decades, patients at public hospitals have been complaining about the service delivery and the state of the institutions. In 2007, a national probability crosssectional survey that was conducted by Powell, Bourne \& Waller [5] found that the health care sector was identified as the eighth leading national problem in Jamaica.

Owing to the complaints of the public on the state of the public sector, the government of Jamaica started the public sector modernization programme. The demands of the public are such that public sector management reform is high on the priority list and they are requesting that modernization and reforms be done with urgency as they are long overdue. A society must be based on trust and with 7 out of every 100 people trusting government and 7 out of 50 individuals trusting other people [5] delayed reforms have all the ingredients of social anarchy.

Wise [12] commenced a research paper entitled 'Public management reform: Competing drivers of change' that "Public management reforms often are portrayed as part of a global wave of change, and all organizational change is interpreted within a single reform paradigm that is rooted in economics and market-based principles. Reforms outside this paradigm go unnoticed" [12, p. 555]. The New Public Management is therefore in keeping with the global changes which are rooted in finances, institutional, political and ideological changes in which organizations must operate.

Long ago the public sector in Jamaica had not responded to their customers' demands and customer satisfaction was rarely discussed as a part of the agenda of the public sector.
Today, as part of the public sector modernization programme, the public sector has to change how it does business and the customer is now at the centre of business focus. Historically, public hospitals in Jamaica would just deliver a service and not bring the patients' needs and satisfaction into sight. But, in 2016, SERHA's vision statement reads. "The vision of the Kingston Public Hospital is to provide service by qualified, efficient, courteous and highly motivated work teams in a clean, secure and attractive environment". It is this reality that resulted in KHP speaking of customer service improvements in 2015 [13].

This research is to give an insight into the client's perception of the services offered by the Health Care Professional in SERHAs. In 2010, SERHA commissioned a 'Waiting time Survey' in order to understand the length of time it took a patient to be seen by a health care practitioner. In order to address customers' satisfaction, $\mathrm{GH}$ implemented measures that have lowered lengthy waiting time [13]. The response of GH to the customer has not ceased with lowering the lengthy waiting time at Accident and Emergency as the "Senior Medical Officer (SMO) for the institution informed JIS News that due to ongoing improvements, they have reduced the lengthy waiting time at GH for surgical procedures" [13].

Although it is the customers of the public hospitals that provide it with business, income and output, the traditional culture of product driven service delivery permeates the operations and the customers are held hostage to the culture instead of the efficiency, profitability, and highest degree of service delivery as expected by customers [14]. The traditional culture of the public health care facilities (PHCF) was without the ingredient of customer satisfaction. According to Kotler and Keller [15], satisfaction is "a person's feeling of pleasure or disappointment resulting from comparing a product's perceived performance in relations to his or her expectations" (p.144). Over time the administration paid little attention to $\mathrm{GH}$ wants to understand how to satisfy the needs of its customers and based on Kotler and Keller's perspective, the users' disappointment may be an indication of poor customer service [15].

Roy, Vaijayanthi and Shreenivasan [16] opined that people have come to expect a high quality service from institutions with which they transact business and with that not being met by Public Health Care Facility (PHCF), made the institution a foe of its users. Following the modernization of public hospitals in Jamaica, there was a need to examine customers' perception of service quality of PHCF as this provided insight into the transformation of the traditional culture and customers' response to the changes made. Hence, the purpose of the study is to examine patient perception on the quality of service by Health care professionals at the two major hospitals in the South East Regional Health Authority (SERHA) (in Jamaica). As such, research objectives are 1) Determine the level of Service Quality Delivery offered by health care professionals at the two major hospitals in the South East Regional Health Authority (SERHA) in Jamaica, and 2) Evaluate whether there is a negative/positive gap between perception and expectation of users regarding the Service Quality Delivery offered by health care professionals at two 
Citation: Ellis JC, Bourne PA, Fallah J, et al. (2019) The Perception of Patients on the Service Quality Offered by Healthcare Professionals at Two Major Public Hospitals in South East Regional Health Authority (Serha), Jamaica. Insights Anthropol 3(2):185-196

major hospitals in the South East Regional Health Authority (SERHA).

\section{Literature Review}

\section{Service quality gap models}

There are five identifiable dimensions of service quality 1) Reliability, 2) Responsiveness, 3) Assurance, 4) Empathy, and 5) Tangibility [17-19]. These dimensions linked consum- er's expectations to specific service characteristic. The measurements of service quality using these dimensions have often been done using the SERVQUAL model (Figure 1 and Figure 2). This model measures service quality based on the difference between what is expected and the customer perception as stated by Parasuraman, et al. [17]. The model has been used to measure both private and public services such as banking [20], fast food industry [20], hotel industry [21] health care local authorities [22]. Therefore, in the true inter-

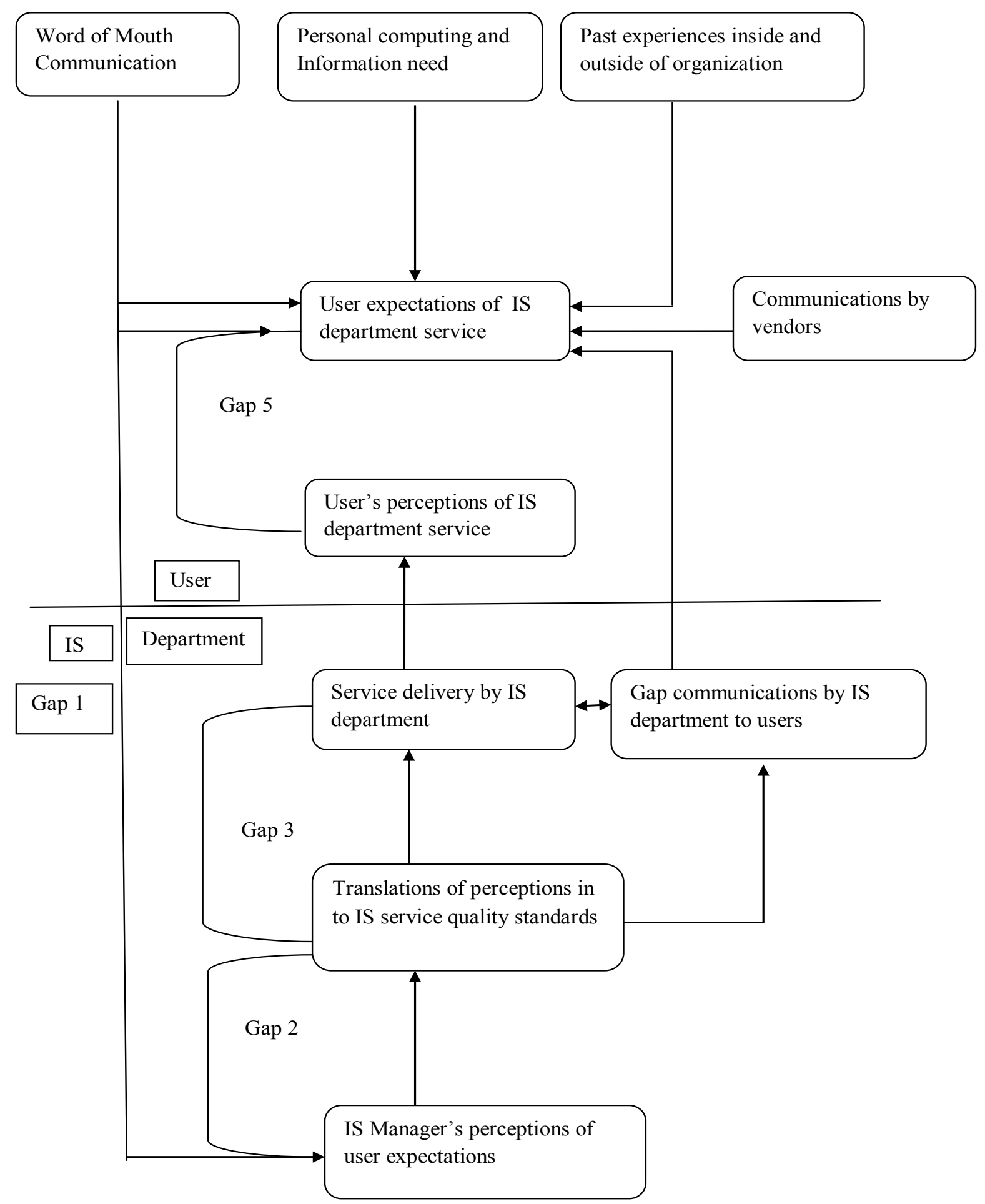

Figure 1: The SERVQUAL Gap Model.

Source: Parasuraman, Zeithaml and Berry [19]. 


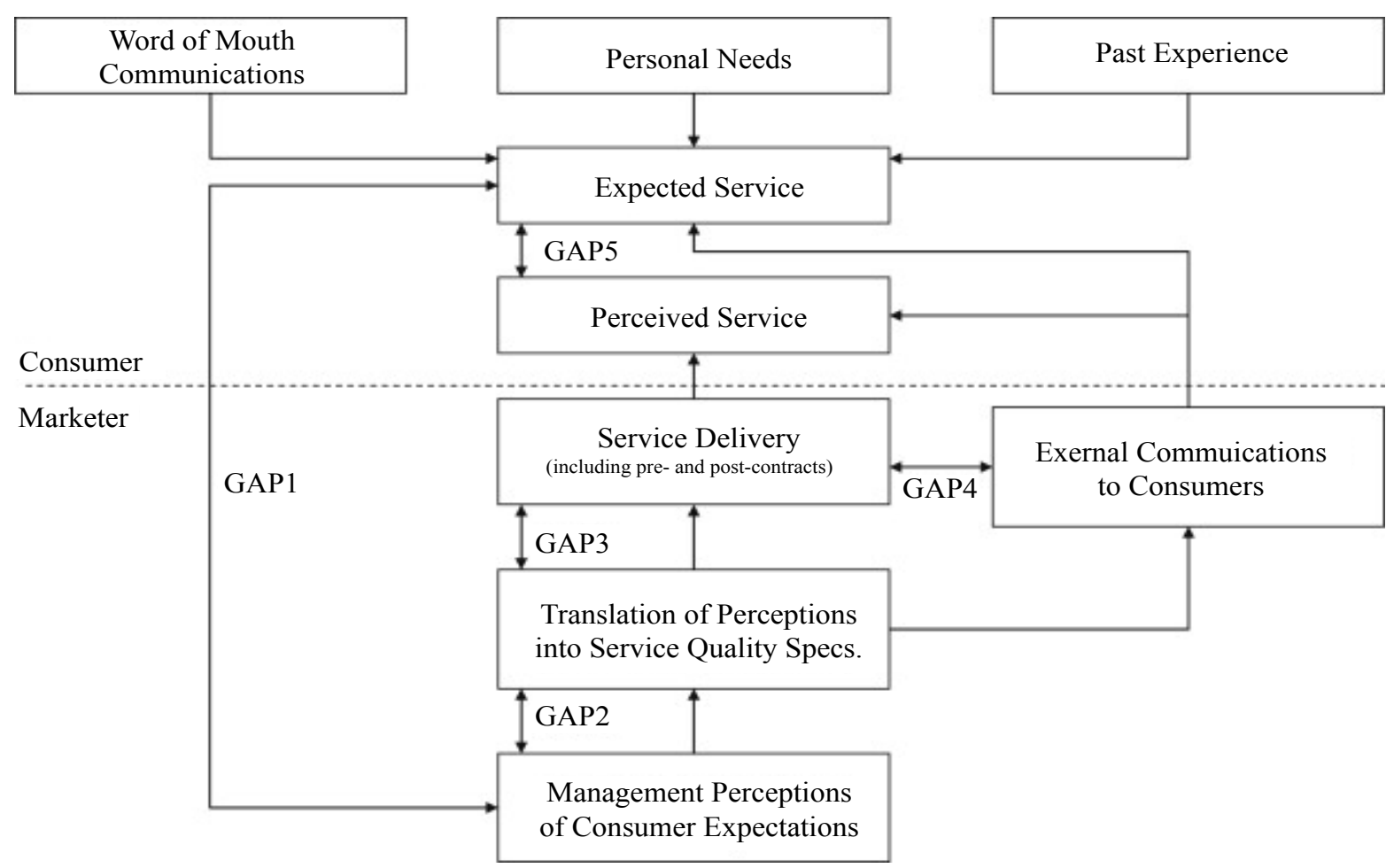

Figure 2: The SERVQUAL Gap Analysis Model.

Source: Kotler and Keller [15].

est of the public, the desired expectation requires the use of the service quality dimensions as the important variables to measure service quality validity [23].

As a result of the various studies that have been done using the SERVQUAL model in various areas [15,17-19,24-31], this study is aimed at building on the works already presented as it relates to public sector reform on service quality. The GAP model by Zeithaml, Parasuraman \& Berry [28], Kotler, and Keller [15], were chosen on the basis that the selected gaps will enable the reader and the researcher to assess how the service dimensions are relatively important to understanding and implementing level of quality service required.

Service Quality Gaps based on Parasuraman, et al. [19] as well as Kotler and Kotler [15], the service quality gaps are differences between 1) The expectations of customers and the perceived service offered, and 2) The expectations of users in relating to service and management's perception of customers' expectations (see also, Rena, et al., 2011). Parasuraman, et al. [19] identified five Gaps in service quality, which emerged between the users and the organization (or department). This was later adopted by Kotler and Kotler [15] who made the differences between users and marketers owing to the marketing perspective with which they wrote.

Based on Parasuraman, et al.'s [19] work, the Gaps were identified as follows:

I Gap: This arose as a result of the difference between customers' expected service and management's perceptions of customers' expectations.

II Gap: This was the variation between management perceptions of customers' expectations and service quality specifications.

III Gap: Being the disparity between service quality specifications and the real service delivery.

IV Gap: The dissimilarity between the service delivered and the external communication about the service with customers.

V Gap: Arising from the difference between consumer expectation and their perception of service quality.

\section{Modifications of service quality model developed by Parasuraman, et al. [19]}

The Service Quality Gap Model developed by Parasuraman, et al. [19] was void of the socio-demographic characteristics of people, which was later included by quality and also to ascertain how factor analysis can be used to identify number of factors Renganathan [32]. The work included the perception of managers about what users expect, which meant that this was Gap 5 in Parasuraman, et al.'s [19]. Model with the inclusion of socio-demographic characteristics (i.e. age, gender, income, and educational level) Table 1.

Renganathan argued that many of the studies on service quality examined the issue from the perspectives of customers and organizations $[15,19]$ and that Zeithamlet, et al. [29] proposed molding customers' expectations and perceptions fitted in a five-dimension service quality [32]). These were 1) Tangibles; 2) Reliability; 3) responsiveness; 4) Assurance, and 5) Empathy. Tangibles: Physical evidence, appearance of physical facilities, personnel, and communication materials. 
Citation: Ellis JC, Bourne PA, Fallah J, et al. (2019) The Perception of Patients on the Service Quality Offered by Healthcare Professionals at Two Major Public Hospitals in South East Regional Health Authority (Serha), Jamaica. Insights Anthropol 3(2):185-196

Table 1: Socio-demographic characteristics of sampled respondents, $\mathrm{n}=358$.

\begin{tabular}{|l|l|}
\hline Details & $\mathrm{N}(\%)$ \\
\hline Gender & \\
\hline Male & $90(25.9)$ \\
\hline Female & $257(74.1)$ \\
\hline Age group & \\
\hline 18-21 years & $26(7.5)$ \\
\hline $22-30$ years & $84(24.3)$ \\
\hline $31-40$ years & $83(24.0)$ \\
\hline $41-50$ years & $67(19.4)$ \\
\hline $51-60$ years & $49(14.2)$ \\
\hline 61+ years & $37(10.7)$ \\
\hline Educational level & \\
\hline Primary & $37(11.2)$ \\
\hline High/Secondary & $198(60.2)$ \\
\hline Tertiary & $84(25.5)$ \\
\hline Post-Tertiary & $10(3.0)$ \\
\hline Patients' visitation & \\
\hline Kingston public hospital & $240(67.2)$ \\
\hline Victoria jubilee hospital & $117(32.8)$ \\
\hline Length of time using service of: & \\
\hline General hospital (GH) - Mean \pm SD & $10.8 \pm 9.4,95 \% \mathrm{Cl}: 7.1-14.5$ \\
\hline Maternity (MH) - Mean \pm SD & $9.6 \pm 9.4,95 \% \mathrm{Cl}: 5.8-13.3$ \\
\hline & \\
\hline
\end{tabular}

Reliability: Ability to perform the promised service dependably and accurately. Responsiveness: Willingness to help customers and provide prompt service. Assurance: Knowledge and courtesy of employees and their ability to convey trust and confidence. Empathy: provision of individualized caring attention to customers [32].

Instead of the initial five Gaps developed by Parasuraman, et al. [19] which included users and provides, Zeithaml, et al. [29] established five Gaps around the perception of users only based on tangibles, reliability, responsiveness, assurance and empathy. The Gap was based on the mean differences between users' expectations and perception.

\section{Customer satisfaction}

Within the context of Kotler's definition of customer satisfaction "a person's feelings of pleasure or disappointment resulting from comparing a product's perceived performance in relations to his or her expectations", it can be deduced from Parasuraman, et al. [19], Kotler and Kotler [15] and Zeithaml, Parasuraman, \& Berry [29] pointed out that if users' perception of service performance is greater than their expectation that satisfaction will be greater and vice versa. The disparity between users' expectations and their belief on service performance holds the key service delivery with excellence and otherwise to customers [33].

The literature provided an extensive conceptual framework, which provided the basis of this study, as there was a gap on a theoretical model on the phenomenon. In summary, the identified constructions in the literature provided all the materials for the execution and carrying out of this work, and additional variables were brought in so as to ensure that all variables that should be included were placed in the econometric model employed in the analysis of the findings.

\section{Methods and Materials}

\section{Research design}

Many scholars have written on social research methodologies but the researcher has found Crotty's [34] work aptly fitting for this project as it summarized the research process in a diagrammatic and systematic manner while providing elaborate details of each component. In the text entitled 'The foundations of social research: Meaning and perspective in the research process', Crotty outlines that the research process can be described using four issue schema: (1) Methods, (2) Methodology, (3) Theoretical perspective, and (4) Epistemology [34-36].

Based on the works of Rea and Parker [37], Babbie [36] and some review of Powell, Bourne and Waller [5], the researcher used a standardized questionnaire. The questionnaire was written in English. There are 37 questions on the standardized instrument, with three (3) Being open-ended items (Questions 1, 3, and 4).

Population and sampling: A hospital based cross-sectional quantitative survey was conducted with 358 participants within the month of June 2017. The population consisted of 240 users at the General hospital and 118 at the Maternity hospital. Both hospitals are located in Metropolis district of Kingston, Jamaica. The sampling technique used was convenient sampling. A team of researchers were dispatched at front foyers/casualty department in each hospital. Participants were arbitrarily asked whether or not they would be willing to participate in a research on customer service offered by the healthcare professionals at the hospitals. In addition to the previously mentioned issues, only those who consented were given an instrument/questionnaire to participate in the research [36].

Sample design: Based on the nature of the study, the researcher sought participants who met the general objective of the work, that is, the users of the facilities. Other individuals who were not cognizant of the issues of this research and could offer no assistance were not used. Therefore, a convenience sampling technique was used. For this study, 358 participants were administered questionnaires. The sample size was decided based on the fact that 2,421 patients are discharged from the wards of the hospitals on a monthly basis, with a confidence interval of $95 \%$, a margin of error of $3 \%$, and response distribution of $50 \%$ given that this is unknown. The information above was determined using a single population proportion formula.

\section{Inclusion and exclusion criteria}

The participants were in-patients (patients who are admitted to a ward and discharged for home) of the two major hospitals in the South East Regional Health Authority 
Citation: Ellis JC, Bourne PA, Fallah J, et al. (2019) The Perception of Patients on the Service Quality Offered by Healthcare Professionals at Two Major Public Hospitals in South East Regional Health Authority (Serha), Jamaica. Insights Anthropol 3(2):185-196

(SERHA). Patients under the age of 18 were excluded from the study. Only in-patients who have the capacity to read and comprehend were allowed to participate.

\section{Measuring instrument}

The measuring instrument was a two-fold respondent questionnaire. The questionnaire was administered to users over the age of 18-years-old. The questions measured demographics and eligibility criteria. Certain broad questions on the users' view on the quality of health services offered at the two major hospitals in the South East Regional Health Authority (SERHA) were used to measure the dependent variables. The quality of health services was measured on the Likert scale in which respondents were asked to rate the present health services being offered on a continuum of strongly agree to strongly disagree. The mean was used to determine the overall level of quality.

\section{The conceptualization and operationalization of variables}

The variables measured were the perceived service quality of health care delivered by the healthcare professionals. The instrument used is a three-section questionnaire.

Each participant was required to complete the abovementioned instrument which was not developed by the researcher. This was an open questionnaire which was developed by Zeithmal, Parasuraman \& Berry [29] to also obtain demographic information including gender, number of years the client had been using the health facility, etc. The questionnaire was a five dimension one which spoke to how satisfaction and expectation were is measured.

\section{Service quality}

Service quality is the difference between customer's perception of service delivery and their expectation of service (see, for example [38-40]) which is embedded in the Service Gap model developed by Parasuraman, et al. [19]. Q = P - E, where $Q$ represents service quality; $P$ being perception of service delivery and $E$ is customers' expectation of service delivery.

\section{Data collection}

Firstly, approval was given by the Ethics Committee of the University of Technology. Secondly, in accordance with the South East Regional Health Authority (SERHA), all Ethical Review Board approval was sought, and authorization letters were obtained from the Regional Director.

The measuring instrument was pre-tested using two users who were not selected as part of the study sample. Feedback obtained was used to make adjustments to the questions in preparation for carrying out the main survey. There was a consent form for the participants. This was further explained to the participants by the researchers and they were allowed to sign without any pressure upon their agreement to participate in the study. Having obtained their consent, the participants were asked to participate in the study by answering a respondent questionnaire lasting no longer than 15-20 minutes. This was administered immediately upon receipt of consent. A code was assigned to each respondent for easy reach should there be a need to contact any respondent post the session.

All questionnaires were checked for completion and consistency. The responses were also checked for omitted questions. This was done by the researchers and field assistants.

\section{Reliability and validity}

Having operationally defined a concept, the measurement device should be both reliable and valid. The reliability of a research instrument concerns the extent to which the instrument yields the same results on repeated trials. Although unreliability is always present to a certain extent, there will generally be a good deal of consistency in the results of a quality instrument gathered at different times. The tendency toward consistency found in repeated measurements is referred to as reliability [41]. External reliability is the more common and refers to the degree of consistency of a measure over time. Internal reliability is mostly important when dealing with multiple-item scales. Validity is the degree to which a test measurement or other device measures what it is intended to measure [42].

To minimize threats to reliability and validity of the study findings, measures such as careful design and pre-testing of the instrument was carried out; this involved standardization of the questionnaires in an effort to reduce bias and ambiguity. As outlined in the section on data collection, the questions were pre-tested to ensure that each participant has a clear understanding of the questions. A standard approach to obtaining responses from participants was maintained as a means of enhancing reliability and validity.

Every effort was made to ensure that the participants were in a suitable environment to eliminate distraction(s), so that their full participation was obtained. Also, every effort was made to ensure that all questionnaires were completed in one session so that any missing data was captured to prevent recall bias which would have resulted if time had elapsed.

\section{Data analysis}

In analyzing the data, all quantitative data was summarized and then entered into the computer using the latest version of Statistical Package for Social Scientists (SPSS) version 21 to conduct the statistical analysis. Data were analyzed using both descriptive and inferential statistics. The Pearson's Chi-Square test was the only inferential measured to assess if a real statistical significant relationship exists between two categorical variables. A real statistical significant relationship was said to exist if $p$ was less than $0.05(p<0.05)$. The variable "the 'length of time in using the General Hospital or Maternity hospital service" was decoded into short and length of time using the median. The median length of time in using the service of the General hospital and Maternity was eight (8) and six (6) years, respectively. Participants who reported that they use the facility less than one (1) year and up to eight years' for General hospital and up to six (6) years for Maternity were categorized as having short period of times, while 
Citation: Ellis JC, Bourne PA, Fallah J, et al. (2019) The Perception of Patients on the Service Quality Offered by Healthcare Professionals at Two Major Public Hospitals in South East Regional Health Authority (Serha), Jamaica. Insights Anthropol 3(2):185-196

those with more than eight (8) and six (6) years were categorized as having moderate-to-long years of using the services.

Scale analysis: The reliability, dimensionality, and validity of all multiple-item measurement scales were investigated. The procedures used are stated below: -

Reliability: Reliability of a research instrument concerns the extent to which the instrument yields the same results on repeated trials [36].

Validity: This is the extent to which a scale or set of measures accurately represents the concept of interest [36]. Discriminant validity is the degree to which two conceptually similar concepts are distinct.

\section{Ethical Issues}

Table 2: Utilization of service at hospitals (i.e., $\mathrm{GH}$ and $\mathrm{MH}$ ), $\mathrm{n}=358$.

\begin{tabular}{|l|l|}
\hline Details & $\mathrm{n}(\%)$ \\
\hline GH & \\
\hline Short-time & $105(56.5)$ \\
\hline Moderate-to-long time & $81(43.5)$ \\
\hline MH & \\
\hline Short-time & $6(60.0)$ \\
\hline Moderate-to-long time & $4(40.0)$ \\
\hline
\end{tabular}

For the purposes of this research proposal ethical approval was sought from UTECH as well as the South East Regional Health Authority (SERHA). The prospective participants were given the assurance that confidentiality and anonymity will be maintained and that the information given was used solely for the purposes of the study unless otherwise permitted. All participants were also required to give their informed consent prior to being admitted in the study. This was done through the providing of information on the study, inviting their participation and requesting the signing of a consent form and was comprised the cover page of the questionnaire.

The participants were also informed that at the end of the study, all questionnaires will be secured in a file inaccessible to other parties and ultimately be destroyed five years post finalization of the research. Anonymity was preserved by the use of code numbers rather than the use of names, as assigned in the sampling frame. All participants were informed that there are minimal risks associated with participation in the study and that they were free to raise questions and concerns throughout the study. They were also informed that they were under no obligation to agree or participate in the study as their participation was voluntary.

Findings: The sampled respondents were 358 patients at the Kingston Public and the Victoria Jubilee hospitals in

Table 3: Analysis of reliability of items and factor loading.

\begin{tabular}{|c|c|c|c|c|c|c|c|c|}
\hline Dimension & No & $\begin{array}{l}\text { Factor } \\
\text { loading }\end{array}$ & Eigenvalue & $\begin{array}{l}\text { Variance } \\
\text { Explained }\end{array}$ & $\begin{array}{l}\text { Cronbach's } \\
\text { (sub-scale) }\end{array}$ & $\begin{array}{l}\text { KMO } \\
\text { (sub-scale) }\end{array}$ & $\begin{array}{l}\text { KMO } \\
\text { (total-scale) }\end{array}$ & $\begin{array}{l}\text { Cronbach's } \\
\text { (total-scale) }\end{array}$ \\
\hline \multirow[t]{4}{*}{ Tangibility } & 1 & 0.392 & 6.380 & 28.999 & 0.666 & 0.693 & \multirow[t]{22}{*}{0.870} & \multirow[t]{22}{*}{0.830} \\
\hline & 2 & 0.673 & & & & & & \\
\hline & 3 & 0.755 & & & & & & \\
\hline & 4 & 0.681 & & & & & & \\
\hline \multirow[t]{4}{*}{ Reliability } & 5 & 0.768 & 2.803 & 41.741 & 0.841 & 0.807 & & \\
\hline & 6 & 0.730 & & & & & & \\
\hline & 7 & 0.745 & & & & & & \\
\hline & 8 & 0.744 & & & & & & \\
\hline \multirow[t]{5}{*}{ Responsiveness } & 9 & 0.734 & 1.748 & 49.685 & 0.641 & 0.653 & & \\
\hline & 10 & 0.655 & & & & & & \\
\hline & 11 & 0.629 & & & & & & \\
\hline & 12 & 0.757 & & & & & & \\
\hline & 13 & 0.661 & & & & & & \\
\hline \multirow[t]{5}{*}{ Assurance } & 14 & 0.755 & 1.092 & 54.648 & 0.284 & 0.510 & & \\
\hline & 15 & 0.825 & & & & & & \\
\hline & 16 & 0.627 & & & & & & \\
\hline & 17 & 0.814 & & & & & & \\
\hline & 18 & 0.612 & & & & & & \\
\hline \multirow[t]{4}{*}{ Empathy } & 19 & 0.744 & 1.060 & 59.422 & 0.804 & 0.772 & & \\
\hline & 20 & 0.778 & & & & & & \\
\hline & 21 & 0.775 & & & & & & \\
\hline & 22 & 0.675 & & & & & & \\
\hline
\end{tabular}


Citation: Ellis JC, Bourne PA, Fallah J, et al. (2019) The Perception of Patients on the Service Quality Offered by Healthcare Professionals at Two Major Public Hospitals in South East Regional Health Authority (Serha), Jamaica. Insights Anthropol 3(2):185-196

Kingston, Jamaica. Of the sampled respondents, the majority were females $(74.1 \%)$, ages $22-30$ years old $(24.3 \%)$, and having obtained a secondary education as highest educational attainment (71.4\%). The average time using the services at Kingston Public hospital is $10.9 \pm 9.4$ times, and $9.6 \pm 9.4$ times for the Victoria Jubilee hospital.

Table 2, presents the utilization of services at the General Hospital (GH) and the Maternity Hospital (MH). Of the sampled respondents $(358), 67.2 \%(n=240)$ utilized the service of the GH compared to $32.8 \%(n=117)$ of the $\mathrm{MH}$. Of those who were sampled from the $\mathrm{GH}(n=240)$, the response rate was $77.5 \%$ ( $n=186)$. Of those who responded, the majority had a short utilization of the service offered by the hospital (i.e., $56.5 \%, n=105)$. On the other hand, only $8.5 \%(n=10)$ of those who utilized the services of the $\mathrm{MH}$ responded to the question of 'How many times have used utilized the service of the hospital?' Furthermore, $60 \%$ of those who utilized and responded to the services of $\mathrm{MH}$ did so on a short-term basis (i.e., less than 6 times).

Factor analysis of construct: Table 3, presents the factor analysis of the construct service Quality (SERVQUAL). There are five sub-scale or components of SERQUAL, with a total explained variance of 59.422 and the contribution of each component is also presented in the table. Furthermore, Kaiser-Meyer-Olkin (KMO) which measures the sampling adequacy is an index used to determine the appropriateness of Principal Component analysis (i.e., factor). It should be noted that high KMO values (i.e., between 0.5 and 1.0) suggest that factor analysis is appropriate and in this case the overall value is 0.870 . In addition, the KMO values for the subscale are between 0.510 and 0.807 , which indicates that the factor analysis is suitable to maintain arrangement of the items for each subscale.

\section{Research Objective One}

The overall and the specified components of service quality are presented in Table 4. Based on the gap for the overall service quality, service delivery is not meeting the general expectations of the patients who utilize the services of the two major hospitals (i.e., -1.0). The negative value indicates a dis-service, which is substantially owing to a lack of empathy (i.e., -1.4$)$, assurance $(-0.8)$, and responsiveness (-0.9). Patients rated the empathy of the healthcare professionals as

Table 4: Service quality of utilization of GH and MH: Overall and components of SERVQUAL.

\begin{tabular}{|c|c|c|c|}
\hline Details & $\begin{array}{l}P \\
(\text { Mean } \pm \text { SD) }\end{array}$ & $\begin{array}{l}E \\
(\text { Mean } \pm \text { SD) }\end{array}$ & $\begin{array}{l}\text { Gap } \\
\text { (i.e., } \mathbf{Q}=\mathbf{P} \text { - E) }\end{array}$ \\
\hline Tangibility & $5.8 \pm 1.0$ & $5.4 \pm 1.3$ & 0.4 \\
\hline Reliability & $5.6 \pm 1.0$ & $5.5 \pm 1.1$ & 0.1 \\
\hline Responsiveness & $3.4 \pm 1.3$ & $4.3 \pm 1.5$ & -0.9 \\
\hline Empathy & $1.4 \pm 2.3$ & $2.8 \pm 2.0$ & -1.4 \\
\hline Overall & $3.7 \pm 0.7$ & $4.7 \pm 0.7$ & -1.0 \\
\hline
\end{tabular}

Table 5: Pearson's product moment correlations of five (5) expectation components of SERVQUAL.

\begin{tabular}{|c|c|c|c|c|c|c|}
\hline & & Tangibility & Reliability & Responsiveness & Assurance & Empathy \\
\hline \multirow[t]{3}{*}{ Tangibility } & Pearson Correlation & 1 & $0.563^{* *}$ & 0.019 & -0.047 & $-0.307^{* *}$ \\
\hline & Sig. (2-tailed) & & $<0.0001$ & 0.729 & 0.379 & $<0.0001$ \\
\hline & $\mathrm{N}$ & 353 & 352 & 352 & 352 & 350 \\
\hline \multirow[t]{3}{*}{ Reliability } & Pearson Correlation & $0.563^{* *}$ & 1 & -0.049 & $0.254^{* *}$ & $-0.212^{* *}$ \\
\hline & Sig. (2-tailed) & $<0.0001$ & & 0.356 & 0.000 & $<0.0001$ \\
\hline & $\mathrm{N}$ & 352 & 352 & 352 & 352 & 350 \\
\hline \multirow[t]{3}{*}{ Responsiveness } & Pearson Correlation & 0.019 & -0.049 & 1 & $0.118^{*}$ & $0.334^{* *}$ \\
\hline & Sig. (2-tailed) & 0.729 & 0.356 & & 0.027 & $<0.0001$ \\
\hline & $\mathrm{N}$ & 352 & 352 & 352 & 352 & 350 \\
\hline \multirow[t]{3}{*}{ Assurance } & Pearson Correlation & -0.047 & $0.254^{* *}$ & $0.118^{*}$ & 1 & $0.418^{* *}$ \\
\hline & Sig. (2-tailed) & 0.379 & $<0.0001$ & 0.027 & & $<0.0001$ \\
\hline & $N$ & 352 & 352 & 352 & 352 & 350 \\
\hline \multirow[t]{3}{*}{ Empathy } & Pearson Correlation & $-0.307^{* *}$ & $-0.212^{* *}$ & $0.334^{* *}$ & $0.418^{* *}$ & 1 \\
\hline & Sig. (2-tailed) & $<0.0001$ & $<0.0001$ & $<0.0001$ & $<0.0001$ & \\
\hline & $\mathrm{N}$ & 350 & 350 & 350 & 350 & 350 \\
\hline
\end{tabular}

${ }^{* *}$ Correlation is significant at the 0.01 level (2-tailed); ${ }^{*}$ Correlation is significant at the 0.05 level (2-tailed). 
Citation: Ellis JC, Bourne PA, Fallah J, et al. (2019) The Perception of Patients on the Service Quality Offered by Healthcare Professionals at Two Major Public Hospitals in South East Regional Health Authority (Serha), Jamaica. Insights Anthropol 3(2):185-196

very low $(2.8 \pm 2.0, Q=-1.4)$, which is account for the negative gap in service quality. Furthermore, the overall expectation of patients on services delivered by both hospitals is moderately higher $(4.7 \pm 0.7$, out of 7.0$)$ than that which is delivery by the institutions (i.e., $3.7 \pm 0.7$, out of 7.0 ). The highest rate was awarded for the equipment and reliability of the service offered by the health institutions; but that the users gave the healthcare professionals a low score on empathy for them (i.e., patients).

Table 5, shows that a direct statistical correlation existed between tangibility and reliability $\left(r_{x y}=0.563, P<0.0001\right)$. This suggests that modern equipment and machines allow for the provision of reliable services by the hospitals. However, the findings also revealed that empathy is inversely associated with 1$)$. Tangibility $\left(r_{x y}=-0.307, P<0.0001\right)$, and 2$)$. reliability $\left(r_{x y}=-0.212, P<0.0001\right)$. A deduction that can be made from those figures is that people believed that more advance equipment and reliable service is resulting with less empathy by the healthcare professional staffers and vice versa. Further extrapolations can be made from the findings that the modernization of equipment and the provision of a reliable service are important in service quality; but that these should be applied with the soft skills (i.e., empathy and assurance). The findings also show that the soft skills (i.e., assurance and empathy) are positively correlated $\left(r_{x y}=0.418, P<0.0001\right)$.

Table 6, presents a statistical analysis of service quality expectation by hospital utilization (i.e., General Hospital (GH) and Maternity Hospital (MH). Patients (i.e., users) of the services by $\mathrm{GH}$ and $\mathrm{MH}$ expect a moderately high service delivery from healthcare professionals and that there is no difference based on whether or not they use either of the two facilities $\left(4.5 \pm 1.1\right.$ and $4.7 \pm 0.6, \mathrm{t}_{351}=-1.240, \mathrm{P}=0.216$, respectively).

Table 7 presents the service quality for the general and the sub-components of SERQUAL (i.e., tangibility, reliability,

Table 6: Independent sample t-test of mean expectations of patients by hospital type.

\begin{tabular}{|l|l|}
\hline Details & Mean \pm SD \\
\hline Service expectations & \\
\hline GH & $4.5 \pm 1.1$ \\
\hline MH & $4.7 \pm 0.6$ \\
\hline
\end{tabular}

etc.) disaggregated by gender of respondents. The findings show that female believed that healthcare professionals are empathetic $(2.86 \pm 2.09)$ compared to their male counterparts $(2.38 \pm 2.09)-\mathrm{t}_{198}=-2.163, P=0.032$. For the other subcomponents, no statistical difference existed between males and females $(P>0.05)$.

\section{Limitation of Study}

This study used a non-probability sampling technique that limits the likelihood of generalizability and repeatability. The methodology of this research was well conceived. In order to maximize the reliability and validity of the research findings, a feasibility study was conducted. The purpose for this study was to mitigate bias and ambiguity in the questions so that standardization could be achieved. Furthermore, pre-testing the questions ensured that the participants have a clear understanding of what was required to answer them. The use of a median to categorize the time range for length of time utilizing the hospital services reduced ambiguity, and defined the timeframe as either short, or moderate-to-long years. However, the method had a shortcoming in the sections: population and sampling, sample design, and inclusion and exclusion criteria. This shortcoming was the failure to include a random sample to reflect the population of both public hospitals. The results, therefore, must be interpreted within the context of the study and there should be no attempt to speak outside of the sampled respondents.

\section{Discussion}

Traditionally in Jamaica, products or services were produced/offered to customers/clients with little attention paid to effective service delivery. The public healthcare system has been found to be among the 8 leading national problems identified by Jamaicans in a national probability cross-sectional survey [5]. The issue is clients/customers/patients have been complaining about the poor quality of services offered by healthcare personnel [1-4] as well as the police [9]. With the SERHA's vision statement being "The vision of the Kingston Public Hospital is to provide service by qualified, efficient, courteous and highly motivated work teams in a clean, secure and attractive environment", this can be partially assessed by evaluating patients' views on service delivered by two of the public hospitals in its charge. Although there are some clear limitations of this study (i.e., based on the sampling technique), the views of the sampled patients provide an in-

Table 7: Overall service quality, sub-components disaggregated by gender.

\begin{tabular}{|c|c|c|c|}
\hline \multirow[t]{2}{*}{ Details } & \multicolumn{2}{|l|}{ Gender } & \multirow[t]{2}{*}{ t-value } \\
\hline & Male & Female & \\
\hline Tangibility & $5.52 \pm 1.31$ & $5.43 \pm 1.31$ & 0.538 \\
\hline Reliability & $5.57 \pm 0.98$ & $5.49 \pm 1.19$ & 0.495 \\
\hline Responsiveness & $4.25 \pm 1.69$ & $4.27 \pm 1.45$ & -0.086 \\
\hline Assurance & $4.21 \pm 1.10$ & $4.19 \pm 1.36$ & 0.152 \\
\hline Empathy & $2.38 \pm 1.65$ & $2.86 \pm 2.09$ & $-2.163^{*}$ \\
\hline Overall & $4.67 \pm 0.59$ & $4.67 \pm 0.81$ & 0.923 \\
\hline
\end{tabular}

${ }^{*} P<0.05$ (i.ie., 0.032). 
Citation: Ellis JC, Bourne PA, Fallah J, et al. (2019) The Perception of Patients on the Service Quality Offered by Healthcare Professionals at Two Major Public Hospitals in South East Regional Health Authority (Serha), Jamaica. Insights Anthropol 3(2):185-196

sight into the service quality of the health care professionals in both public healthcare hospitals. On average, the patients have been utilizing the services of both public hospitals for at least 9.5 years, which means that they are appropriate and suitable to assess the service quality delivered by healthcare professionals employed by the institution. The findings revealed that patients expect more service quality than what they are receiving, which is a starting point in fulfilling the vision of SERHA and this is no different from what obtains for the Jamaica Police [9].

The current findings found that a majority of patients used the hospital service for a short period of time. This was evident where $56.5 \%$ of patients were short term users at $\mathrm{GH}$, compared to $43.5 \%$ of patients who were moderate-tolong time users. For $\mathrm{MH}, 60 \%$ of patients were short term users compared to $40 \%$ were moderate-to-long time users. The implications of this findings mean that they can provide administrators and policy makers with pertinent assessment of service deliverables by healthcare professional employed by the aforementioned hospitals. The reality is, the majority of the patients are moderately satisfied with the services provided by the healthcare professionals compared to an expectation that is greater than perceived service offering. Clearly there is a high level of dissatisfaction that must be addressed in how services are provided to patients at these public hospitals, and emphasis must be placed on service quality approach by the healthcare professionals. Healthcare professionals at both hospitals must begin to internalize the patients as their customers, and so they should serve their healthcare needs. The rationale for the customer driven hospital sector is embedded in a perspective forwarded by Ramseook-Munhurrun, Lukea-Bhiwajee, and Naidoo (2010) "Public sector services are responsible and accountable to citizens and communities as well as to its customers" (p. 40). It is on the premise of the aforementioned perspective as well as the current negative gap in service quality that healthcare professionals of the two public hospitals in SERHA should begin to refashion how they conceptualize and deliver quality service to their customers. The negative gap in service quality (i.e., perception - expectation or performance) for the current study does concur with the public sector in Mauritius [43] as well as for the police force in Jamaica [9] and Taiwan [44].

In Ramseook-Munhurrun, Lukea-Bhiwajee, and Naidoo's [43] as well as in Chen, Lee, Chen, \& Tsai's study [44], all the sub components of SERQUAL had a negative value, which is also the case in this study. For the current study, the overall gap was -1.0 , and this negative gap suggests that there was disservice due to a lack of empathy $(-1.4)$, assurance $(-0.8)$ and responsiveness (-0.9) among customers who access and utilize the services at the two major hospitals in SERHA. The patients did have a favorable opinion on the reliability (0.1) and tangibility (0.4) components; this indicated that patients trusted the physical resources of the hospitals; but not the healthcare professionals due to their low level of empathy. It must also be mentioned that the -1.0 value also showed that patients had high expectations of the service from the hospitals, but the actual delivery of service was less than that was expected. The high level of dissatisfaction among customers for services offered by public hospitals in Jamaica can be likened to the customer service offered by the public sector in Mauritius.

The findings of this study are highlighting the fact that healthcare professionals in the two public hospitals have failed to understand the needs and expectations of targeted customers, which concurs with the work of Bateson [45]. Healthcare facilities are service institutions that must meet the needs of their targeted customers. If policy makers and the healthcare professionals intend to solve the identified service quality deficiency at $\mathrm{GH}$ and $\mathrm{MH}$, they must revert to understanding the needs and expectations of their customers. Simply put, they must begin to see patients as customers that have needs, which must be met. In fact, according to Ravichandran, K., Prabhakaran, S. and Arun Kuma S [46], “Dimensions of SERVQUAL items such as solving the customer problems, service delivery on time, quick response to customer request, safe transactions, personal attention and understanding the needs of the customer appear to be fertile areas for future inquiry" [46, p. 160], which must be understood as some of the expectations of customers at public hospitals in Jamaica in order to satisfied the patients' expectations.

The present findings showed that there was a direct statistical correlation between tangibility and reliability $\left(r^{x y}=\right.$ $0.563, p<0.0001$ ). This indicated that the hospital equipment allowed for the reliable delivery of service to the patients. The data also showed that empathy was inversely correlated with tangibility $\left(r_{x y}=-0.307, p<0.0001\right)$, and reliability $\left(r_{x y}=-0.212\right.$, $p<0.0001)$. This finding could be interpreted as patients believing that advanced medical equipment and reliable service is causing healthcare professionals to become less empathetic, and vice versa. The interpersonal skills assurance and empathy are positively correlated $\left(r_{x y}=0.418, p<0.0001\right)$. This correlation could indicate that human interaction is integral in providing quality service to patients, thus allowing patients to trust their healthcare providers. However, correlations among the components of SERQUAL are somewhat different from the literature. Mahiah., Suhaimi., \& Ibrahim's work [47] found that assurance, empathy, reliability, responsiveness and tangibility were highly and significantly correlated with one another, which were not the case in the current study. It could be concluded from the data, that interpersonal skills such as empathy and assurance must be improved in conjunction with the modernization of hospital equipment and providing reliable service, so that service quality can be enhanced.

\section{Recommendation}

Owing to the fact that results are showing that the patients are somewhat satisfied with the service offered by the healthcare professionals at two of the public hospitals in SER$\mathrm{HA}$, it is important that further studies be done to continue monitoring the service delivery. In the literature review $Q=$ P-E. Q-represents quality, P-represents perception and E represent expectation. Perhaps future studies could explore other gaps as this will provide insights for policy implementation. In order to maintain optimal patient satisfaction, implement 
Citation: Ellis JC, Bourne PA, Fallah J, et al. (2019) The Perception of Patients on the Service Quality Offered by Healthcare Professionals at Two Major Public Hospitals in South East Regional Health Authority (Serha), Jamaica. Insights Anthropol 3(2):185-196

a customer service complaints system where feedback can be received via telephone and other electronic media. Periodic customer service surveys are also important. Most importantly, have written customer service standards and ensure that all staff members are made aware of them.

\section{Conclusion}

The sampled clients of this study are somewhat highly satisfied with the service offered to them by healthcare professionals in two of the major public hospitals in Jamaica; but service deliverables are not meeting their expectations. Although there is constraint on the generalizability of the current findings, the results offer invaluable insights into service quality of healthcare professionals at the two studied hospitals. Nevertheless, with this being a pioneer study on the customer service in public hospitals in Jamaica, the findings will be benchmark for future research and interpretation of results. It could be concluded from the data, that interpersonal skills such as empathy and assurance must be improved in conjunction with the modernization of hospital equipment and providing reliable service, so that service quality can be enhanced.

Patients' perception of service is an important framework for examining the quality of healthcare service delivery, and improvement in such requires analyses at different interval to aid understanding. The Government of Jamaica (GOJ) has long recognized the importance of establishing frameworks to safeguard the service quality of healthcare delivery offered by public healthcare professionals. The traditional culture of the public health care facilities (PHCF) was without the ingredient of customer satisfaction. According to Kotler and Keller [15], satisfaction is "a person's feeling of pleasure or disappointment resulting from comparing a product's perceived performance in relations to his or her expectations". [15, p.144]. Over time public hospitals have been a point of focus, as it faces with challenges in relation to customer centered healthcare delivery that could be in keeping with fulfilling the vision of SERHA. Healthcare professionals in Jamaica should begin to depart from the production driven model to a customer-based service model as they impacts on the service as well as the health (i.e., mind and body) of people.

\section{References}

1. Hibbert K (2015b) Those eventful visits to KPH, spanish town hospital. Kingston: Jamaica observer.

2. Hibbert K (2015a) GH horror: Daughter says hospital workers' negligence, bad treatment sped up dad's death. Kingston: Jamaica Observer.

3. Hussey-Whyte D (2014) Mothers vow never to return to victoria jubilee: After claims of inhumane treatment. Kingston: Jamaica Observer.

4. Jamaica Observer (2010) Patients urged to make use of formal complaints process. Kingston: Jamaica Observer.

5. Powell LA, Bourne P, Waller L (2007) Probing jamaica's political culture, volume 1: Main trends in the july-august 2006 leadership and governance survey. Kingston: Centre for leadership and governance, department of government, university of the west indies, mona, jamiaca.
6. South East Regional Health Authority (SERHA) (2016a) Kingston public hospital: Fact sheet. Kingston: SERHA.

7. South East Regional Health Authority (SERHA) (2016b) Victoria jubilee hospital: Fact sheet. Kingston: SERHA.

8. Hall J, Wynter E (2003) Kingston public hospital: The high seat of medicine in jamaica. Kingston.

9. Bourne PA (2016) Customer satisfaction of policing the jamaican society: Using SERVQUAL to evaluate customer satisfaction. J Healthcare Communication 1: 3.

10. (2016) Jamaica Ministry of Health. Annual Report 2015. Kingston: Ministry of health, Jamaica.

11. Virtue E (2016) Bed shortage crippling public hospitals again. Kingston: Jamaica Gleaner.

12. Wise LR (2002) Public management reform: Competing drivers of change. Public Administration Review 62: 555-567.

13. Jamaica Observer (2015) Service improves at GH, say Senior Medical Officer. Kingston: Jamaica Observer.

14. Harriott A (2000) Police and crime control in Jamaica: Problems of reforming ex-colonial constabularies. Kingston: University of the West Indies Press.

15. Kotler P, Keller LK (2006) A Frame work for Marketing Management. ( $3^{\text {rd }}$ edn), Pearson, Prentice Hall, New Jersey, 194.

16. Roy R, Vaijayanthi P, Shreenivasan KA (2011) Service quality gap of foreign banks in india using pzb service quality model an empirical study. International conference on software and computer applications IPCSIT 9.

17. Parasuraman A, Zeithaml VA, Berry LL (1988) SERVQUAL: A multiple-item scale for measuring consumer perceptions of service quality. Journal of Retailing 64: 12-40.

18. Parasuraman A, Berry LL, Zeithaml VA (1991b) Refinement and reassessment of the SERVQUAL scale. Journal of Retailing 67: 420-450.

19. Parasuraman A, Zeithaml VA, Berry LL (1985) A conceptual model of service quality and its implications for future research. Journal of Marketing 49: 41-50.

20. Cronin JJ, Taylor SA (1992) Measuring service quality: A reexamination and extension. Journal of Marketing 56: 52-68.

21. Brown SW, Swartz TA (1989) A gap analysis of professional service quality. Journal of Marketing 53: 92-98.

22. Scott D, D Shieff (1993) Service quality components and group criteria in local governments. International Journal of Service Industry Management 4: 42-53.

23. Payne A (1995) The essence of service marketing. Prentice-Hall International (UK) Ltd, London.

24. Asubonteng P, McCleary KJ, Swan JE (1996) SERVQUAL revisited: A critical review of service quality. The Journal of Services Marketing 10: 62-81.

25. Parasuraman A, Berry LL, ZeithamI VA (1991a) Perceived service quality as a customer-based performance measure: An empirical examination of organizational barriers using an extended service quality model. Human Resource Management 30: 335-364.

26. Parasuraman A, ZeithamI VA, Berry LL (1994) Reassessment of expectations as a comparison standard in measuring service quality: Implications for further research. Journal of Marketing 58: 111-124. 
Citation: Ellis JC, Bourne PA, Fallah J, et al. (2019) The Perception of Patients on the Service Quality Offered by Healthcare Professionals at Two Major Public Hospitals in South East Regional Health Authority (Serha), Jamaica. Insights Anthropol 3(2):185-196

27. Ramasaran-Fowdar RR (2007) Developing a service quality questionnaire for the hotel industry in Mauritius. Journal of Vacation Marketing 13: 19-27.

28. Zeithamal VA, Berry LL, Parsuraman A (1993) The nature and determinants of customer expectations of service. Journal of the Academy of Marketing Science 21: 1-12.

29. ZeithamI VA, Parasuraman A, Berry LL (1990) Delivering quality service: Balancing customer perceptions and expectations. The Free Press, New York.

30. Babakus E, Boller GW (1992) An empirical assessment of SERVQUAL scale. Journal of Business Research 24: 253-268.

31. Cody K, Hope B (1990) EX-SERVQUAL: An instrument of measure service quality extranets. Proc $10^{\text {th }}$ Australasian Conference on Information System.

32. Renganathan R (2011) Service quality in hospitality services: Gap model and factor analysis. European Journal of Social Sciences 26: 159-175.

33. Maglio PP, Kieliszewski CA, Spohrer JC (2010) Introduction: Why a handbook?. In: Maglio PP, Kieliszewski JA, Spohrer JC, Handbook of Service Science. Springer, New York, 1-7.

34. Crotty M (2005) The foundations of social research: Meaning and perspective in the research process. SAGE, London.

35. Kuhn TS (1996) The structure of scientific revolutions. ( $3^{\text {rd }}$ edn), The university of chicago press, Chicago.

36. Babbie $E$ (2007) The practice of social research. (10 th edn), Wadsworth, a Division of Thomson Learning, International.

37. Rea LM, Parker RA (2005) Designing and conducting survey research: A comprehensive guide. ( $3^{\text {rd }}$ edn), Jossey-Bass, San Francisco.
38. Pitt LF, Watson RT, Kavan CB (1995) Service quality: A measure of information systems effectiveness. MIS Quarterly 19: 173-187.

39. Kettinger WJ, Lee CC (1994) Perceived service quality and user satisfaction with the information services function. Decision Sciences 25: 737-766.

40. Kettinger WJ, Lee CC (1995) Exploring a 'gap' model of information services quality. Information Resources Management Journal 8: 5-16.

41. Carmines EG, Zeller RA (1991) Reliability and validity assessment. Sage Publications, Newbury Park.

42. Mosby Inc (2009) Mosby's Medical Dictionary. ( $8^{\text {th }}$ edn), Mosby, St. Louis.

43. Ramseook-Munhurrun P, Lukea-Bhiwajee SD, Naidoo P (2010) Service quality in the public service. International Journal of Management and Marketing Research 3: 37-50.

44. Chen CM, Lee HT, Chen SH, et al. (2014) The police service quality in rural Taiwan: A comparative analysis of perceptions and satisfaction between police staff and citizens, Policing. An International Journal of Police Strategies and Management 521-542.

45. Bateson JEG (1990) Evaluating the role and place of marketing in service firms. Service Management Effectiveness 13: 324-342.

46. Ravichandran K, Prabhakaran S, Arun Kuma S (2010) Application of servqual model on measuring service quality: A bayesian approach. Enterprise Risk Management 1: E9.

47. Mahiah S, Suhaimi S, Ibrahim A (2006) Measuring the level of customer satisfaction among employees of human Resource Division. Advances in Global Business Research 3.

DOI: $10.36959 / 763 / 501$

Copyright: (C) 2019 Ellis JC, et al. This is an open-access article distributed under the terms of the Creative Commons Attribution License, which permits unrestricted use, distribution, and reproduction in any medium, provided the original author and source are credited. 